\title{
Sexual assertiveness in women with and without substance-dependent husbands: A comparative study
}

\section{Zeinab Haghparast}

Shahid Beheshti University of Medical Sciences School of Nursing and Midwifery

Hedyeh Riazi ( $\nabla$ h.riazi@sbmu.ac.ir)

Shahid Beheshti University of Medical Sciences School of Nursing and Midwifery https://orcid.org/0000-0003-0346-3396

\section{Jamal Shams}

Shaheed Beheshti University of Medical Sciences

Farzane Ahmadi

Shahid Beheshti University of Medical Sciences

Research article

Keywords: Sexual Behavior, Assertiveness, Substance-Related Disorders, Spouses

Posted Date: August 2nd, 2019

DOI: https://doi.org/10.21203/rs.2.11166/v1

License: (c) (i) This work is licensed under a Creative Commons Attribution 4.0 International License. Read Full License 


\section{Abstract}

Background Sexual assertiveness is one of the main issues in sexual relationship between couples. Since substance dependence might disrupt this relationship the present study was designed and conducted to assess and compare sexual assertiveness in women with and without substance-dependent husbands Methods This was a cross-sectional study. The Hurlbert Index of Sexual Assertiveness (HISA) was used. The data then were compared between women with and without substance-dependent husbands. Results In all 300 women with and without substance-dependent husbands entered into the study. The mean age of the women was $37.31 \pm 8.79$ and $32.70 \pm 7.24$ years, and the mean duration of their marriage was $15.92 \pm 9.40$ and $12.08 \pm 8.92$ years, respectively. The majority of women with substance-dependent husbands had primary education (40.3\%) and the majority of those with non-substance-dependent husbands had higher (37.3\%). The mean score of sexual assertiveness was $50.66 \pm 14.31$ in the women with substance-dependent husbands and $58.42 \pm 13.86$ in those with non-substance-dependent husbands $(P<0.001)$. Conclusions The risk of lower assertiveness for women with substance-dependent husbands was 2.2 times more than women with non-substance-dependent husbands. The husband's substance dependency is therefore an issue that is worthy of attention in sexual and marital counseling. Sexual assertiveness can be improved in women with substance-dependent husbands through the implementation of appropriate interventions, such as educational and counseling programs.

\section{Background}

Sexual assertiveness refers to the individual's ability to recognize, prioritize and express her limitations, needs and desires in sexual encounters [1], and includes constructs such as the ability to initiate sexual activity, the non-acceptance of unwanted sexual activities and the use of contraceptives, and can help promote healthy sexual behaviors [2]. Higher levels of sexual assertiveness are associated with increased libido and sexual activity, orgasm, sexual satisfaction and marital satisfaction [3] and reduced high-risk sexual behaviors [4]. Sexual assertiveness has a direct relationship with sexual self-esteem and sexual and marital satisfaction [5], and helps increase relationship satisfaction [6]. Low levels of sexual assertiveness further expose the individual to negative experiences in sexual situations, such as rape or forced sex [7].

One of the problems that may affect women's sexual issues is their husband's substance dependence. Many studies have shown that substance dependence in men can affect sexual function and cause problems such as the lack of libido, erectile and orgasm dysfunction and even sexual violence [8-14]. On the other hand, the consumption of the substance in the man affects the spouse's sexual desire and function $[15,16]$. Studies have shown that intimate relationship between spouses also have some problems due to drug abuse [17]. Therefore, it can be argued that the use of substances by affecting the sexual performance of the individual and his wife and by disrupting the couple's intimate relationships can also affect sexual assertiveness. 
A significant proportion of the population in the world, including in Iran, suffer from substance abuse [18, 19]. Despite many studies focused on the problems of these individuals and their families, and in particular their wives [14-16, 20,21], none have addressed this issue in view of sexual assertiveness, which is an important factor that affects the quality of marital life. Many studies have also investigated the level of sexual assertiveness and related factors in different groups [1, 3, 5, 7, 22, 23], but to our knowledge, none have addressed sexual assertiveness in view of the husband's substance dependence. The present study was therefore designed and conducted to determine and compare the level of sexual assertiveness in women with substance-dependent husbands and women with non-substance-dependent husbands. Sexual assertiveness in women is of prime of importance since it relates to women's sexual satisfaction which in turn could lead to a more sustainable family for married women. When a sexual partner of a woman is a drug user, then providing evidence on the topic could be very essential in order to improve women's sexual life.

\section{Methods}

\section{Study Participants}

The study population consisted of two groups. Group one included women with substance-dependent husbands, and group two included women living in Tehran who reported no history of substance dependence in their husbands. The sample size was 300 in this study, including 150 women with substance-dependent husbands and 150 women with non-substance-dependent husbands. The inclusion criteria for both groups of women consisted of Iranian nationality in the woman and her husband, no infertility, no history of substance dependence in the woman, the couple's age range being 18-50 years, and no diseases or use of medications affecting sexual function.

Another inclusion criterion for the women with a non-substance-dependent husband was having a husband who had no history of substance dependence.

\section{Procedure}

The present cross-sectional study was conducted in 2018 in Tehran, Iran. To select the women with substance-dependent husbands, substance abuse treatment centers were visited and women whose husbands were referred for treatment, at the first visit and before starting treatment were invited to take part in the study, and questionnaires were distributed among those who consented to participate. To select the women whose husbands were not substance-dependent, five centers were randomly selected from 44 Comprehensive Health Centers affiliated to Shahid Beheshti University of Medical Sciences in Tehran, and the eligible women who visited these centers were selected through convenience sampling on a voluntary basis.

Data collection 
The Hurlbert Index of Sexual Assertiveness (HISA): This study assessed sexual assertiveness using the HISA, which includes 25 items scored based on a 5-point Likert scale from 'always' to 'never', where the scores range from 0 to 100, and where higher scores imply higher levels of sexual assertiveness and lower scores indicate less sexual assertiveness $[3,24]$. The level of sexual assertiveness was determined by scoring the subjects' responses on a scale as follows: Always $=0$, Mostly $=1$, Sometimes $=2$, Rarely $=3$ and Never $=4$ points. The following items were reverse-scored: 3, 4, 5, 7, 12, 15, 16, 17, 18, 21, 22 and 23. This index has a constructed content validity and an internal consistency of 0.91 [3] and has been used in many studies and has favorable validity and reliability $[23,24]$.

\section{Statistical analysis}

Data were analyzed in SPSS-17. The quantitative variables were described using the mean and standard deviation, and the qualitative variables by frequency (percentage). The two groups were compared using the Chi-square and Fisher's exact test. The two groups were compared in terms of sexual assertiveness using the independent t-test or one-way analysis of variance. Finally the association between assertiveness and independent variables was examined using logistic regression analysis. As such proportion to the mean score of the sexual assertiveness, the study samples were categorized into two groups: those who scored equal or greater than mean and those who scored lower. Then all independent variables that significantly differed between women with and without substance dependent partner entered into the model. The level of statistical significance was set at $5 \%$.

\section{Ethical Considerations}

The research code of ethics was obtained from the Ethics Committee of Shahid Beheshti University of Medical Sciences (IR.SBMU.PHNM.1395.569). For sampling, the researcher first introduced herself to the candidates, explained the study objectives and ensured them of their anonymity and the confidentiality of their data, and distributed the questionnaires among them after they had completed the written consent forms.

\section{Results}

The mean age of the women with and without substance-dependent husbands was $37.31 \pm 8.79$ and $32.70 \pm 7.24$ years, respectively, and their mean duration of marriage was $15.92 \pm 9.4$ and $12.08 \pm 8.92$ years. The majority of the women with substance-dependent husbands had primary education $(40.3 \%)$ and the majority of those with non-substance-dependent husbands had a higher education (37.3\%). Table 1 presents the characteristic details of the study groups. There were significant differences between the two groups with regard to woman's and husband's age and education, husband's occupation, economic status and duration of marriage but any significant differences were found regarding the variables of woman's occupation, woman and husband's age at marriage and number of children (Table 1).

The mean score of sexual assertiveness was 50.66 in the women with substance-dependent husbands and 58.42 in those with non-substance-dependent husbands (Table 2). The independent t-test showed a 
significant difference between the two groups in terms of this score $(P<0.001)$.

Drugs consumed in the dependent group included $42 \%$ opioids (opium, heroin, methadone), $15.3 \%$ stimulants (methamphetamine) and $42.7 \%$ more than one kind of substance. The duration of dependency in the majority of cases (23.3\%) was 6-10 years. In $56 \%$ of cases, there was a dependency at the time of marriage and $90.7 \%$ of cases had the previous history of substance abuse treatment. There was a significant relationship between the type of substance consumed and sexual assertiveness in the group of women with substance-dependent husbands $(p=0.039)$.

However, some variables could increase the risk of low assertiveness, but among all variables only a significant association was observed between sexual assertiveness and addiction $(P=0.004)$. The risk of lower assertiveness for women with addicted husbands was 2.2 times more than women who did not have addicted husbands (Table 4).

\section{Discussion}

According to the present study, the women with substance-dependent husbands had a lower sexual assertiveness than the women with non-substance-dependent husbands. Other studies have also confirmed the effect of substance dependence in men on their spouse's sexual life $[15,16]$, which may be attributed to the higher prevalence of sexual dysfunction in men with substance dependence $[8,9]$.

Various studies have shown that the prevalence of sexual dysfunction is higher in men with substance dependence compared to men without $[10,11]$. A total of $40.9 \%$ of the men with substance abuse suffer from some kind of sexual dysfunction, with the most common being erectile dysfunction [11], which has a reported prevalence that is three times higher than in the general public [10]. Previous studies have shown that the long-term use of alcohol and opioids causes dysfunction in all the aspects of the individual's sexual function [8]. High levels of alcohol consumption increase the risk of erectile dysfunction [25]. The persistent use of opioids leads to reduced libido and orgasm. Heroin consumption reduces the individual's frequency of sexual activity per week, the desire for having sex, the degree of sexual arousal and the ability to reach orgasm [12]. The long-term use of cocaine also reduces sexual desire and function and may cause problems in reaching orgasm [13]. High doses of amphetamine are associated with the loss of sexual arousal and orgasm dysfunction [26]. In a recent study conducted on substance abusers, almost half of the subjects reported a loss of libido and sexual pleasure, function and behavior, and the other half reported an increase in these cases [9]. It seems that sexual dysfunction in these people and their disrupted ability to establish favorable and satisfactory sexual relationships with their partners reduce their self-confidence and desire for re-establishing a sexual relationship and gradually distance them from their spouse and reduce intimacy and affection in the couple. A reduced quality of sexual relationships can lead to sexual dysfunction in women with substance-dependent spouses and result in the women's loss of interest in expressing their sexual desires and ultimately cause a lower sexual assertiveness [27]. Other studies have also shown that women with substance-dependent husbands have problems in the phases of sexual desire, arousal and orgasm, experience a reduced 
frequency of sex, a transformed attitude toward sex and even a disgust with sex, and the women's interest in expressing their sexual priorities and needs to their spouse and thereby their sexual assertiveness diminish $[7,15,16]$. These problems occur because sex is basically a mutual relationship between two partners, and the problems of one partner can affect the other [7]. A couple's satisfaction with their sex life increases their sexual demand and the desire to further initiate sexual activities and find deeper pleasures. Sexual satisfaction and marital satisfaction have a positive correlation with sexual assertiveness $[2,23,28]$. Other studies have shown that the husband's substance dependence affects the couple's intimate relationships and causes communication difficulties and concerns about the future and even a decision to leave or stay with their spouse [17].

According to some studies, violence and wife battering are more prevalent among substance-dependent men $[14,20]$, and these problems can affect sexual assertiveness, since the woman's affection for her husband gradually diminishes upon witnessing such behaviors, and she ends up being dissatisfied with her marital relationship. Clearly, a woman who is subjected to her husband's unaffectionate or violent behaviors will have no interest in expressing her sexual desires. This finding agrees with the results of other studies [7].

Previous studies have shown that depression, anxiety and stress levels are higher in families with substance-dependent members, and this issue imposes tremendous amounts of mental pressure on women and affects their sexual behaviors, responses and interactions [29-32, 17]. Emotional stress, the lack of socioeconomic security, poverty and tumultuous living conditions, which are more frequently witnessed in such families, can attenuate self-belief and self-esteem, and studies have shown that people's self-esteem affects their sexual assertiveness [5]. A woman with poor self-esteem and self-belief cannot daringly appear in sexual encounters and express her sexual needs and interests and is more exposed to the harms associated with low sexual assertiveness.

A limitation of this study was that the questionnaires were completed in a self-report format by the participants, and since their information about the issue in question was insufficient, collecting more accurate data about the duration of their husbands' dependency or the frequency of seeking treatment was impossible. Also, it was impossible to control some potentially important individual confounders, for instance knowledge or attitudes toward sexual assertiveness.

\section{Conclusion}

The women with substance-dependent husbands were less sexually assertive than the women with nonsubstance-dependent husbands. Paying further attention to this issue in families consumed by addiction is crucial. The implementation of special educational programs and planning and offering sexual counseling by sex therapists and addiction counselors and paying particular attention to women with substance-dependent husbands are recommended for improving women's sexual assertiveness and quality of sexual life and achieving greater marital satisfaction. These measures are a step toward the 
promotion of sexual health in these families and reducing the vulnerability of these women and their families.

\section{Abbreviations}

HISA: Hurlbert Index of Sexual Assertiveness

\section{Declarations}

Funding: The study is not supported by any grant.

Authors' contributions: ZH collected the data. HR designed the study and supervised it. JS was involved in data interpretation. FA participated in data analysis.

Ethics approval and consent to participate: The present study has been approved by the Ethics Committee of Shahid Beheshti University of Medical Sciences (IR.SBMU.PHNM.1395.569). Written informed consent was obtained from all individual participants included in the study.

Consent for publication: Consent to publish from the participants was obtained.

Competing interests: The authors declare that they have no competing interests.

\section{References}

1. Zerubavel N, Messman-Moore TL. Sexual victimization, fear of sexual powerlessness, and cognitive emotion dysregulation as barriers to sexual assertiveness in college women. Violence Against Women. 2013;19(12):1518-1537.

2. Morokoff PJ, Quina K, Harlow LL, Whitmire L, Grimley DM, Gibson PR, Burkholder GJ. Sexual Assertiveness Scale (SAS) for women: development and validation. J Pers Soc Psychol. 1997;73(4):790.

3. Hurlbert DF. The role of assertiveness in female sexuality: A comparative study between sexually assertive and sexually nonassertive women. J Sex Marital Ther. 1991;17(3):183-190.

4. Santos-Iglesias P, Sierra JC. El papel de la asertividad sexual en la sexualidad humana: una revisión sistemática. Int J Clin Health Psychol. 2010;10(3).

5. Ménard AD, Offman A. The interrelationships between sexual self-esteem, sexual assertiveness and sexual satisfaction. Can J Hum Sex. 2009;18(1-2):35-45.

6. Lee J-y. Predictors of Female College Students' Relationship Satisfaction: Attachment and Sexual Assertiveness. Psychol Stud (Mysore). 2017;62(1):70-74. 
7. Santos-Iglesias P, Sierra JC, Vallejo-Medina P. Predictors of sexual assertiveness: The role of sexual desire, arousal, attitudes, and partner abuse. Arch Sex Behav. 2013;42(6):1043-1052.

8. Grover S, Mattoo SK, Pendharkar S, Kandappan V. Sexual dysfunction in patients with alcohol and opioid dependence. Indian J Psychol Med. 2014;36(4):355.

9. Bosma-Bleeker MH, Blaauw E. Substance use disorders and sexual behavior; the effects of alcohol and drugs on patients' sexual thoughts, feelings and behavior. Addict Behav. 2018;87:231-237.

10. Chekuri V, Gerber D, Brodie A, Krishnadas R. Premature ejaculation and other sexual dysfunctions in opiate dependent men receiving methadone substitution treatment. Addict Behav. 2012;37(1):124-126.

11. Diehl A, Pillon SC, dos Santos MA, Rassool GH, Laranjeira R. Sexual dysfunction and sexual behaviors in a sample of Brazilian male substance misusers. Am J Mens Health. 2016;10(5):418-427.

12. Palha AP, Esteves M. A study of the sexuality of opiate addicts. J Sex Marital Ther. 2002;28(5):427437.

13. Rawson RA, Washton A, Domier CP, Reiber C. Drugs and sexual effects: role of drug type and gender. J Subst Abuse Treat. 2002;22(2):103-108.

14. Adib-Hajbaghery M, Karimi R, Karbasi H, Haji-Rezaei M, Aminolroayaee E. Comparing violence against women with and without an addicted spouse in Kashan, Iran. Addict Health. 2015;7(1-2):74.

15. Abnavi MA, Ahmadi J, Hamidian S, Ghaffarpour S. Female Sexual Dysfunction Among the Wives of Opioid-Dependent Males in Iran. Int J High Risk Behav Addict. 2016;5(1).

16. Noori R, Rafiey H, Narenjiha H, Assari S, Lankarani MM. Impact of spouse's opiate dependence on the partner's sexual function. J Family Reprod Health. 2008;2(4).

17. Wilson SR, Lubman DI, Rodda S, Manning V, Yap MB. The personal impacts of having a partner with problematic alcohol or other drug use: descriptions from online counselling sessions. Addict Res Theory. 2018;26(4):315-322.

18. Amin-Esmaeili M, Rahimi-Movaghar A, Sharifi V, Hajebi A, Radgoodarzi R, Mojtabai R, Hefazi M, Motevalian A. Epidemiology of illicit drug use disorders in Iran: prevalence, correlates, comorbidity and service utilization results from the Iranian Mental Health Survey. Addiction. 2016;111(10):1836-1847.

19. Degenhardt L, Whiteford HA, Ferrari AJ, Baxter AJ, Charlson FJ, Hall WD, Freedman G, Burstein R, Johns N, Engell RE. Global burden of disease attributable to illicit drug use and dependence: findings from the Global Burden of Disease Study 2010. The Lancet. 2013;382(9904):1564-1574.

20. Gilbert L, El-Bassel N, Chang M, Wu E, Roy L. Substance use and partner violence among urban women seeking emergency care. Psychol Addict Behav. 2012;26(2):226. 
21. Copello A, Templeton L, Powell J. The impact of addiction on the family: Estimates of prevalence and costs. Drugs (Abingdon Engl). 2010;17(sup1):63-74.

22. Auslander BA, Baker J, Short MB. The connection between young women's body esteem and sexual assertiveness. J Pediatr Adolesc Gynecol. 2012;25(2):127-130.

23. Azmoude E, Firoozi M, Sahebzad ES, Asgharipour N. Relationship between Gender Roles and Sexual Assertiveness in Married Women. Int J Community Based Nurs Midwifery. 2016;4(4):363.

24. Pierce AP, Hurlbert MK. Test-retest reliability of the Hurlbert Index of Sexual Assertiveness. Percept Mot Skills. 1999;88(1):31-34.

25. Chew KK, Bremner A, Stuckey B, Earle C, Jamrozik K. ORIGINAL RESEARCH-ERECTILE DYSFUNCTION: Alcohol Consumption and Male Erectile Dysfunction: An Unfounded Reputation for Risk? J Sex Med. 2009;6(5):1386-1394.

26. Gonzales R, Mooney L, Rawson RA. The methamphetamine problem in the United States. Annu Rev Public Health. 2010;31:385-398.

27. Jones AC, Robinson WD, Seedall RB. The Role of Sexual Communication in Couples' Sexual Outcomes: A Dyadic Path Analysis. J Marital Fam Ther. 2018;44(4):606-623.

28. Hurlbert DF, Apt C, Rabehl SM. Key variables to understanding female sexual satisfaction: An examination of women in nondistressed marriages. J Sex Marital Ther. 1993;19(2):154-165.

29. Homish GG, Leonard KE, Kearns-Bodkin JN. Alcohol use, alcohol problems, and depressive symptomatology among newly married couples. Drug Alcohol Depend. 2006;83(3):185-192.

30. Orford J, Velleman R, Copello A, Templeton L, Ibanga A. The experiences of affected family members: A summary of two decades of qualitative research. Drugs (Abingdon Engl). 2010;17(sup1):44-62.

31. Orford J, Copello A, Velleman R, Templeton L. Family members affected by a close relative's addiction: The stress-strain-coping-support model. Drugs (Abingdon Engl). 2010;17(sup1):36-43.

32. Dawson DA, Grant BF, Chou SP, Stinson FS. The impact of partner alcohol problems on women's physical and mental health. J Stud Alcohol Drugs. 2007;68(1):66-75.

\section{Tables}

Due to technical limitations, the tables are only available as downloads in the supplemental files section.

\section{Supplementary Files}

This is a list of supplementary files associated with this preprint. Click to download. 
- Table3.jpg

- Table1.jpg

- Table4.jpg

- Table2.jpg 